\title{
Experimental research of turbo-codes application in telemedicine systems with wireless body area sensor networks
}

\begin{abstract}
The paper shows telemedicine system with wireless body area sensor networks as a potential technology to provide extremely high quality and convenience for people. We discuss a communication process unit with turbo-codec, that can work with necessary requirements, such as extremely low signal power and high reliability of data transmission. also, the turbo-encoding and decoding math is briefly overviewed. the simulation of turbo-codec work in these networks is shown. experimental functions of bit error rate are found.

Streszczenie. W artykule przedstawiono system telemedyczny z bezprzewodowyą siecią czujników umieszczaną w obszarze ciała jako potencjalną technologię, która ma zapewnić wyjątkowo wysoką jakość i wygodę dla ludzi. Przedstawiony proces komunikacyjny może pracować przy wymaganiach tj. wyjątkowo niska moc sygnału i wysoka niezawodność transmisji danych. (Eksperymentalne badania zastosowań turbo-kodów w systemach telemedycznych z bezprzewodowymi sieciami czujników ciała).
\end{abstract}

Keywords: communication technologies, error-correcting code, MAP, SOVA

Słowa kluczowe: technologie komunikacyjne, kod korekcji błędów, MAP, SOVA

\section{Introduction}

The evolution of science and technics has allowed to create a promising application of wireless sensor networks, that is called wireless body area sensor networks (WBAN). It has a huge potential for the revolutionary transformation of medical technologies [1-3]. WBAN can be used to provide assistance to automatic medical treatment, automatic dosing, and vital signal monitoring. Fig. 1 shows an intuitive view of automatic medical treatment process (closed loop control) [2]. At the first step various vital data are collected using different sensors attached to a person. These data are sent to the command unit. At the second step the command unit decides the corresponding treatment method or correct dosing based on the received vital parameters. After this the command unit sends a command to the action unit. At the third step the action unit applies the treatment or dosing to objectives. When the treatment or dosing is finished, sensors will collect updated vital data and the process enters another circulation.

WBAN can provide a healthcare service in a more comfortable, convenient and economical way, than other conventional methods. WBAN provide the ability to broadcast multiple vital parameters in "online" mode, that provides an indispensable aid for people, who suffer from chronic diseases and acute attacks, allowing to react to the worsening of the disease. This is a key technology of "online" (contrast to the Holter "offline" monitoring) prevention of cardiovascular diseases (myocardial infarction or other abnormal conditions). The tumors diagnostics without biopsy may be done on the basis of the work of many miniature sensors, that can detect cancer cells. WBAN can help people with asthma by the way of monitoring airborne allergens and providing medics some "alert signals" in real time mode. Also this technology can be integrated into the telemedicine system, that provides unobtrusive ambulatory monitoring and medical information exchange between professionals in order to improve the treatment quality of the patients $[4,5]$.

WBAN technical implementation is as follows [2,4]: the special sensors are fixed on the certain organs and transmit statistical data via wireless protocol to different devices, that display detailed information about the patient's condition. The controlling action is produced on the results of processing the information. A sensor node consist of data sensing, data processing and communicating components. The communication requirements of WBANs are described in many good works $[2,3,6-9]$. Due to the application area WBANs do not require very large network sizes, but must meet the safety requirements and be friendly on the biological parameters, because the work environment is associated with the human body. WBANs are intended for transmission over short distances, but with the higher data rate via communication channels. So, the extremely low power and high reliability requirements of WBANs make the communication challenge [8]. These requirements induce a need of a good error-correction code in the channel coding scheme $[4,10]$. For overcome this challenge, we research the potential of usage turbo-codes for communication in WBANs, because it is the most effective method for information transmission in channels with low energy consumption in many communication systems. This code is an iterative probabilistic method of error-correcting coding with the reliable performance, that is very close to the Shannon theoretical limit $[11,12]$. So, the work objective is an experimental research of the turbo-code work effectiveness in WBANs.
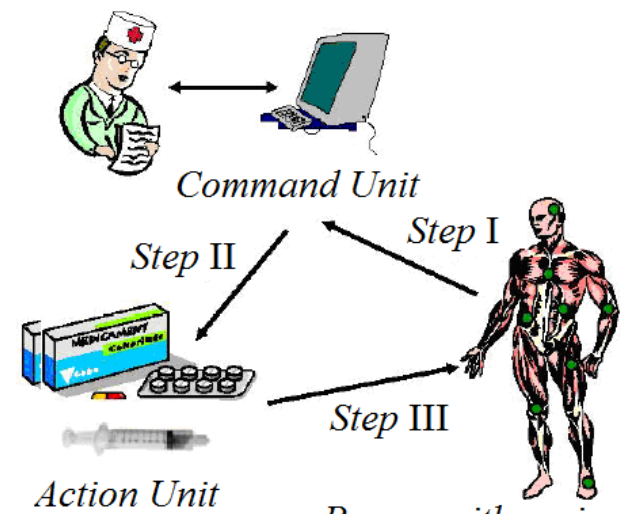

Person with vart
Fig.1. Medical treatment process in WBAN

The paper is organized as follows. Section II briefly describes the turbo-principle and the mathematical apparatus, that is used in turbo-process. In Section III we present an experiments with various parameters to estimate the turbo-code work effectiveness in WBANs. The paper is finally concluded in Section IV. 


\section{Brief description of the turbo-process}

The main principle of the classical turbo-encoding (Fig. 2 ) is the usage of two parallel working constituent encoders, although you can use the arbitrary dimension encoders. The information block $X=d_{k, 1}$ is encoded twice, the second time - after the preliminary random shuffle of information bits (interleaving process $\pi$ ). Interleaver or permutator is an especially important element in the turbo-code construction, that helps to create the stream of independent errors (eliminate error packets), and also enables to encrypt information during the encoding process with the usage of different keys, creating a so-called crypto-coding turbo-code system [4]. The perforation patterns are used to increase the data rate [13].

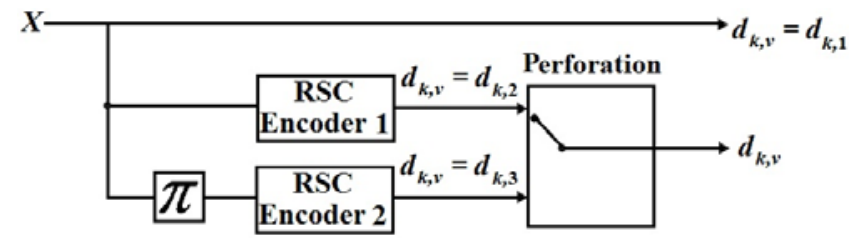

Fig.2. Two-dimensional turbo-encoder

The concept of "log-likelihood ratio" (LLR) is used in the turbo-decoding process [14]. The terms a priori, a posteriori and extrinsic information are the central concepts behind the iterative decoding of turbo-codes (Fig. $3)$. The a priori information $L L R_{a p r}\left(d_{k}\right)$ about a binary symbol $\mathrm{dk}$ is the infor mation known before decoding starts. The extrinsic information $L L R_{\text {ext }}\left(d_{k}\right)$ is the information provided by a decoder based on the received sequence and on a priori information. The a posteriori information $L L R\left(d_{k}\right)$ is the information, that decoder gives taking into account all available sources of the information about bit $\mathrm{dk}$. The decoded information from the first (second) decoder output is used as a priori information for the second (first) decoder input in order to clarify the decoding result using some "soft" decoding algorithms, that minimize the bit error probability. After exiting from the second decoder output the "soft" values of the extrinsic log-likelihood ratio is deinterleaved $\pi-$ 1 and "hard" decision on the transmitted data bit is accepted $[13,15]\left(d_{k}=1\right.$, if $L L R\left(d_{k}\right)>0$ and $d_{k}=0$ otherwise). The channel characteristics and $L L R_{c h}$ have a weak effect on the exchange of a priori, extrinsic and a posteriori information from the decoders in the noisy channels, but their effect is amplified in good channels, so at the lower signal-noise values turbo-codes show better results [16-20].

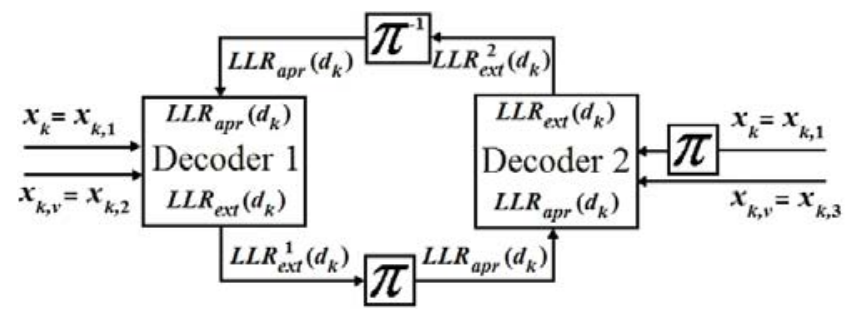

Fig.3. Two dimensional turbo-decoder ( $x k-$ noisy version of the systematic bit; $x k, v-$ noisy versions of the parity-check bits)

High turbo-code efficiency is caused by special soft iterative decoding algorithms, that are called soft-output Viterbi algorithm (SOVA) and maximum a posteriori probability algorithm (MAP or iterative BCJR) [21].

The SOVA differs from the classical Viterbi algorithm [22], in that it uses a modified path metric $M_{k}\left(s_{k}\right)$ on the trellis for state $s$ at the stage $k$, that takes into account the a priori probabilities of the input symbols, and produces a soft output indicating the reliability of the decision using metrics on trellis and add-compare-select operation block. The symbol-by-symbol SOVA algorithm [23] is evaluate the reliability of the binary symbol $d_{k}$ based on Hagenauer's formula for obtained maximally likelihood path on trellis with a sliding window of size $\delta$ in the form

$$
\begin{aligned}
& L L R_{\text {SOVA }} \approx d_{k} \cdot \min _{\substack{i=0, \ldots \delta \\
d_{k} \neq d_{k}^{i}}}\left(\left|M_{k}^{d_{k}=+1}\left(s_{k}\right)-M_{k}^{d_{k}=-1}\left(s_{k}\right)\right|\right)= \\
& =d_{k} \cdot \min _{\substack{i=0 . \ldots \delta \\
d_{k} \neq d_{k}^{\delta}}} \Delta_{k}^{i}
\end{aligned}
$$

The bidirectional SOVA algorithm [23] is performed twice (forward and backward), and a posteriori decisions are calculated using the next rule: if the difference between the magnitude of forward a posteriori decision $\operatorname{LLR}_{S O V A}\left(d_{k}\right)$ and backward solution $L L R_{S O V A}^{\leftarrow}\left(d_{k}\right)$ more than 0 , the result is $L L R_{S O V A}^{\rightarrow}\left(d_{k}\right)$, in otherwise $-L L R_{S O V A}^{\leftarrow}\left(d_{k}\right)$.

The MAP [23] is symbol-by-symbol decoding algorithm with high decoding complexity. The generalized expression for the LLR computation procedure for the MAP decoding algorithm has the form

$$
\begin{aligned}
& \operatorname{LLR}_{M A P}\left(d_{k}\right)=L L R_{c h} \cdot x_{k}+L L R_{a p r}\left(d_{k}\right)+ \\
& +L L R_{e x t}\left(d_{k}\right)=\ln \frac{\sum_{d_{k}=+1}^{\left(s^{\prime}, s\right)} \alpha_{k-1}\left(s^{\prime}\right) \cdot \gamma_{k}\left(s^{\prime}, s\right) \cdot \beta_{k}(s),}{\sum_{d_{k}=-1}^{\left(s^{\prime}, s\right)} \alpha_{k-1}\left(s^{\prime}\right) \cdot \gamma_{k}\left(s^{\prime}, s\right) \cdot \beta_{k}(s)}
\end{aligned}
$$

where: $\quad \alpha_{k}(s)=\sum_{\left(s^{\prime}, s\right)} \gamma_{k}\left(s^{\prime}, s\right) \cdot \alpha_{k-1}\left(s^{\prime}\right)-$ forward path metric on trellis for recursive systematic convolutional (RSC) code; $\beta_{k-1}\left(s^{\prime}\right)=\sum_{\left(s^{\prime}, s\right)} \gamma_{k}\left(s^{\prime}, s\right) \cdot \beta_{k}(s)$ - backward path metric; $\gamma_{k}\left(s^{\prime}, s\right)-$ rib metric, that is calculated as:

$$
\gamma_{k}\left(s^{\prime}, s\right) \approx \exp \left(\begin{array}{l}
\frac{1}{2} \cdot\left(d_{k} \cdot L L R_{a p r}\left(d_{k}\right)\right)+ \\
+d_{k} \cdot L L R_{c h .} \cdot x_{k}+ \\
+\left(\sum_{k=2}^{n} d_{k, v} \cdot L L R_{c h .} \cdot x_{k, v}\right)
\end{array}\right) .
$$

The log-MAP turbo-decoder works in the log-domain. The complicated log-exponential sum is simplified with the Jacobian logarithm [24], that consists of the max operation along with some correction function, such as:

$$
\begin{aligned}
& f(x, y)=\ln \left(e^{x}+e^{y}\right)=\max (x, y)+ \\
& +\ln \left(1+e^{-|x-y|}\right)=\max (x, y)+f_{c o r}(z)
\end{aligned}
$$

The logarithmic metrics in formula 4 are used in the logMAP algorithm for reducing the computational complexity. The manner in which the correction function is calculated is critical to the performance and complexity of the decoding. Several methods have been proposed to simplify its computation [25-26] that gives a tradeoff between complexity and performance, but these decoding algorithms are also suboptimal. For example, max-log-MAP[23] algorithm reduces the complexity of the Jacobian logarithm implementation by omitting the compensation function. The more accurate approximation for calculation the compensation function is presented in the piecewise-linear $(\mathrm{PL}) \log -\mathrm{MAP}$ [25-27] algorithm. It is shown in the next formula [28-30]. 
(4)

$$
f_{c o r}(z)=\left\{\begin{array}{rll}
-0,3792 \cdot z+0,6754, & \text { if } & z \in[0 ; 1) ; \\
-0,2229 \cdot z+0,5327, & \text { if } & z \in[1 ; 1,5) \\
-0,1483 \cdot z+0,4213, & \text { if } & z \in[1,5 ; 2) \\
-0,0773 \cdot z+0,2758, & \text { if } & z \in[2 ; 3) ; \\
-0,0300 \cdot z+0,1362, & \text { if } & z \in[3 ; 4] ; \\
+0,0100, & \text { if } & z \in(4 ; \infty) .
\end{array}\right.
$$

This approximation is very precise (best root mean square error RMSE and correlation coefficient $r$ ) versus many other approximations [25-26,31]. There isn't much difference between log-MAP and PL-log-MAP algorithms in their effectiveness. In the next section we will show this fact with the usage of the simulation.

\section{Simulation of the turbo-codec work effectiveness in WBAN}

For simulation [31-32] the work of the digital communication unit in WBAN we use Monte-Carlo method; BPSK modem and turbo-codec with two identical RSC encoders with $m=2$ tail bits for termination the first encoder and polynomial code generator $g=(7,5)_{8}$; code rate $R=$ $1 / 3$; random interleaver with Park-Miller random generator; additive white Gaussian noise (AWGN) channel with Ziggurat algorithm for modeling standard normally distributed random variables; the energy per bit to noise power spectral density ratio $E_{b} / N_{0}=[0: 3] \mathrm{dB}$ with step 0,25 $\mathrm{dB}$; stopping rule is 10 frames with errors; bit error rate (BER) counter with magic GENIE rule. The experimental results are presented in Fig. 4-8 as a function BER = $f\left(E_{b} / N_{0}\right)$. In Fig. 9 is shown the testing for multimedia data [32, 28-29].

\section{- Experiment \#1.}

The work characteristics of turbo-decoders with different data decoding algorithms are researched. The data packet has a $q=1024$ binary symbols; code rate $R=1 / 3$; $Q=8$ turbo-decoding iterations (Fig. 4).

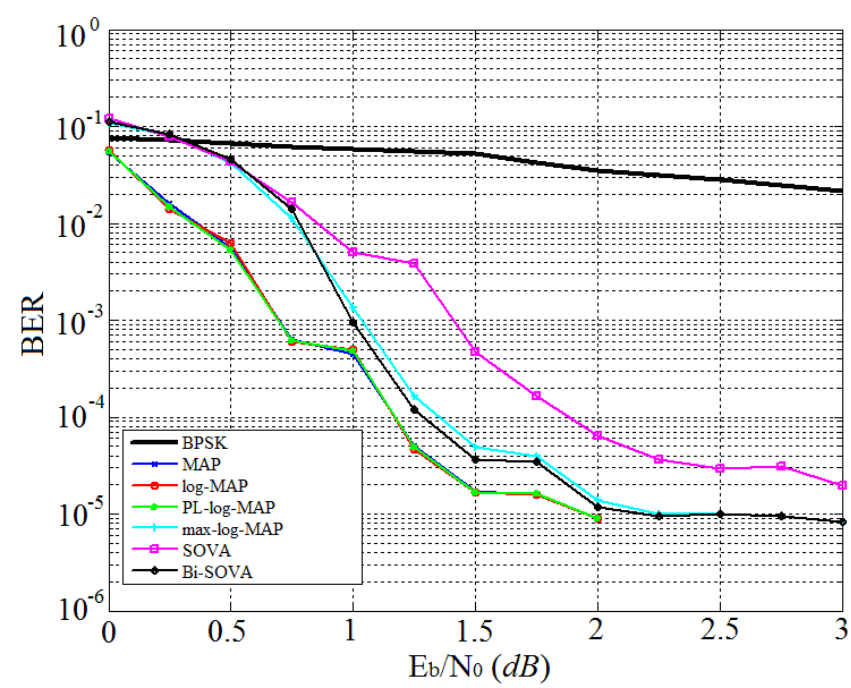

Fig.4. Results of the experiment 1 (different iterative decoding algorithms)

Generally PL-log-MAP algorithm almost achieves BER of log-MAP (RMSE $=0,0005, r=0,9998)$ and MAP (RMSE $=0,0004, r=0,9997)$ turbo-decoding algorithms, but has a lower computational complexity. PL-log-MAP algorithm works better, than other existing MAP modifications, especially in small $E_{b} / N_{0}$ area. If $E_{b} / N_{0}$ value is higher, than 3-4 $d B$, that BER is not heavily depends on the correction function. So, BER of the MAP modifications is approaching to BER of max-log-MAP. Algorithms MAP, log-MAP, PL-log$M A P$ enable to get a significant energy gain compared to the SOVA $\left(0,5-0,6 d B\right.$ for BER $=10^{-3}-10^{-4}, 1,3 d B$ for BER = $\left.10^{-5}\right)$; Bi-SOVA, max-log-MAP $(0,1-0,7 d B)$. So, in our next experiments 2-5 we use PL-log-MAP turbo-decoding algorithm, because it has some advantages.

\section{- Experiment \#2.}

Different values of decoding iterations $Q$ are used, namely, from 1 to 8 (Fig. 5).

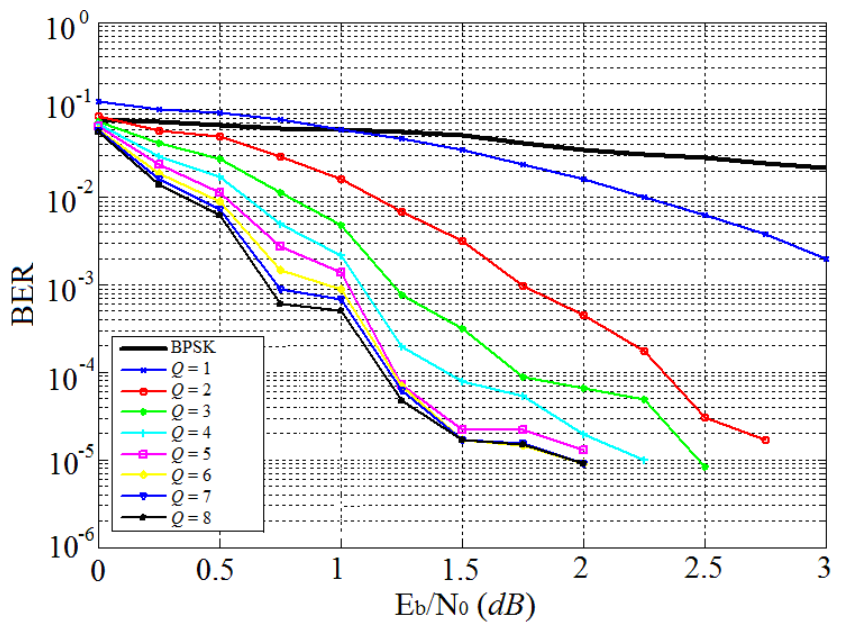

Fig.5. Results of the experiment 2 (different number of decoding iterations)

\section{- Experiment \#3}

Different numbers of the memory cells $m=[2,3,4]$ and polynomial code generators $g=\left[(7,5)_{8},(15,17)_{8},(37,21)_{8}\right]$ are used for RSC encoders (Fig. 6).

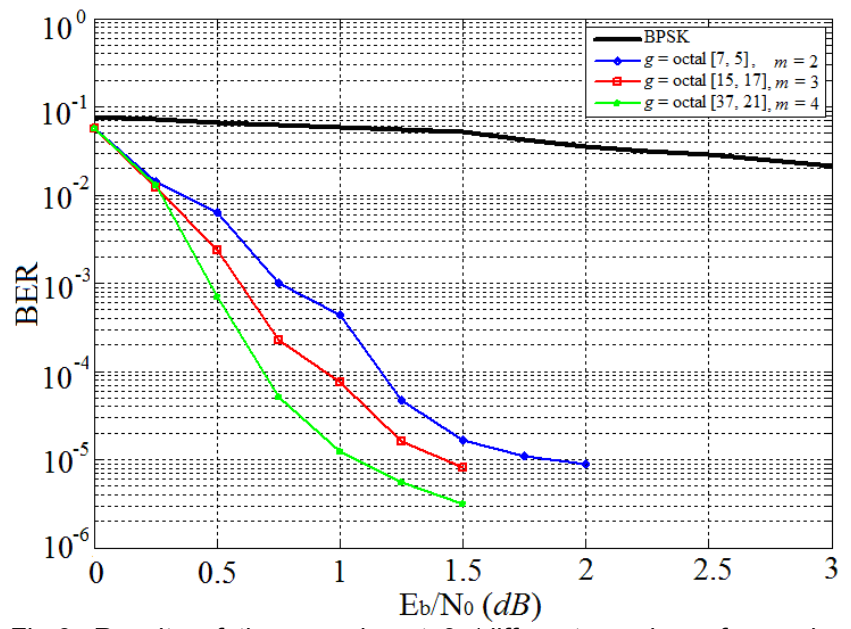

Fig.6. Results of the experiment 3 (different number of encoder memory cells and polynomial code generators)

\section{- Experiment \#4}

Different coding rates $R=[1 / 2,1 / 3]$ are applied; $Q=[1$, 4 , 8] decoding iterations; $q=[256,1024,4096]$ binary symbols in the frame (Fig. 7, 8).

It can be seen from Fig. 5, that the PL-log-MAP turbodecoding results are improved by increasing $Q$. For example, with 4 iterations of the turbo-decoder work we received $B E R \approx 1,95 \cdot 10^{-5}$ (by $2 d B$ ), but the same $B E R$ value is achieved for 7 iterations of data decoding at $E_{b} / N_{0}$ $=1,75 \mathrm{~d} B$, that is, the energy gain from the number of iterations is $0,25 d B$. As the $E_{b} / N_{0}$ increases, the number of decoding iterations, which is required to achieve the needed $B E R$, is reduced. In addition, it should be noted, that, when $Q>8$, it is possible to achieve a slight energy gain $(0,01-$ $0,06 d B$ ) for a certain BER [33-36]. 


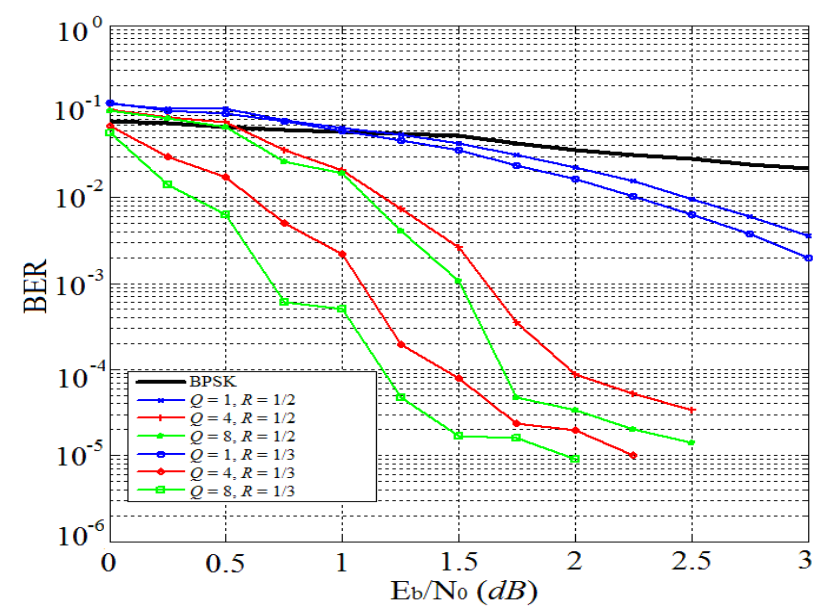

Fig.7. Results of the experiment 4 (different code rates, different number of decoding iterations)

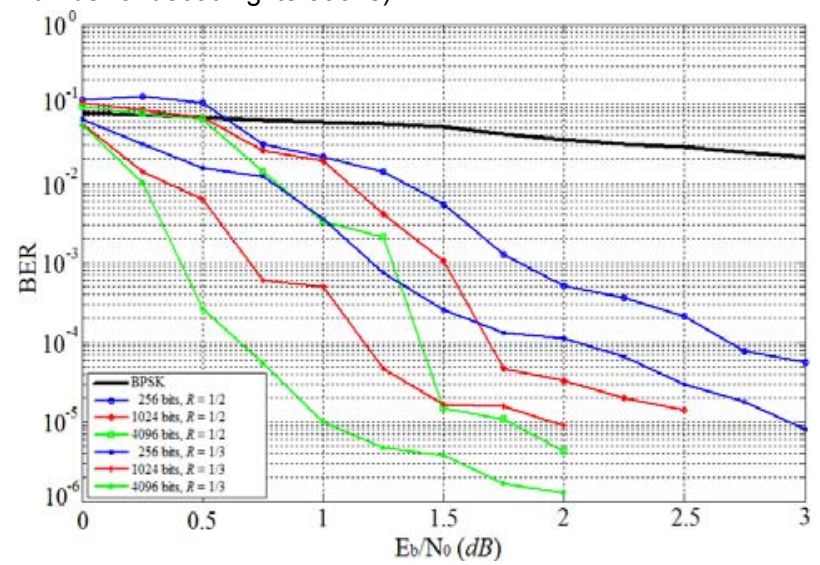

Fig.8. Results of the experiment 4 (different code rates, different number of binary symbols in the frame)

It can be seen from Fig. 5, that the PL-log-MAP turbodecoding results are improved by increasing $Q$. For example, with 4 iterations of the turbo-decoder work we received $B E R \approx 1,95 \cdot 10^{-5}$ (by $2 d B$ ), but the same $B E R$ value is achieved for 7 iterations of data decoding at $E_{b} / N_{0}$ $=1,75 \mathrm{~dB}$, that is, the energy gain from the number of iterations is $0,25 d B$. As the $E_{b} / N_{0}$ increases, the number of decoding iterations, which is required to achieve the needed $B E R$, is reduced. In addition, it should be noted, that, when $Q>8$, it is possible to achieve a slight energy gain $(0,01$ $0,06 d B$ ) for a certain BER [33-36].

The effectiveness of the decoding process is improved by increasing the number of encoder memory cells. An analysis of Fig. 6 at the value $E_{b} / N_{0}=1 d B$ indicates, that the energy gain from an increasing $m$ is $\approx 0,25 d B$ for $\mathrm{BER} \approx 10^{-5}$.

Reducing the encoding rate $R$ allows to achieve an energy gain of $0,25 d B$ for $Q=1 ; \approx 0,5 d B$ for $Q=4$; $\approx 0,75 d B$ for $Q=8$ at $B E R \approx 1,4 \cdot 10^{-5}$ (Fig. 7). Analysis of Fig. 8 shows, that for a frame with 256 bits, the energy gain from the usage of rate $R=1 / 3$ compared to $R=0,5$ is $\approx 0,5$ $d B$; for $q=1024$ bits at BER $\approx 10^{-5}-1 d B$; for $q=4096$ bits at $\mathrm{BER} \approx 4 \cdot 10^{-6}-0,75 d B$. Large sizes of interleaver allow to receive the lower BER, that is an advantage from the interleaver. For example, for the code rate $R=1 / 3$ and $q=$ 4096 bits $B E R \approx 9,98 \cdot 10^{-6}$ is reached on the $E_{b} / N_{0}=1 d B$, and a close $B E R \approx 8,98 \cdot 10-6$ for 1024 bits occurring at $2 d B$ (energy gain $\approx 1 d B$ ), and for 256 bits the BER $\approx 8,04 \cdot 10^{-6}$ corresponds to $3 d B$ (energy gain $\approx 2 d B$ ).

\section{- Experiment \#5}

System testing was performed on the images in the high noise conditions. The example of the result for value $E_{b} / N_{0}$ = $1 \mathrm{~dB}$ for computer image "lena.jpg" with 768 frames and
4096 bits per frame is shown in Fig. 9, where BEN and SEN are the number of bit and symbol errors respectively [3740].

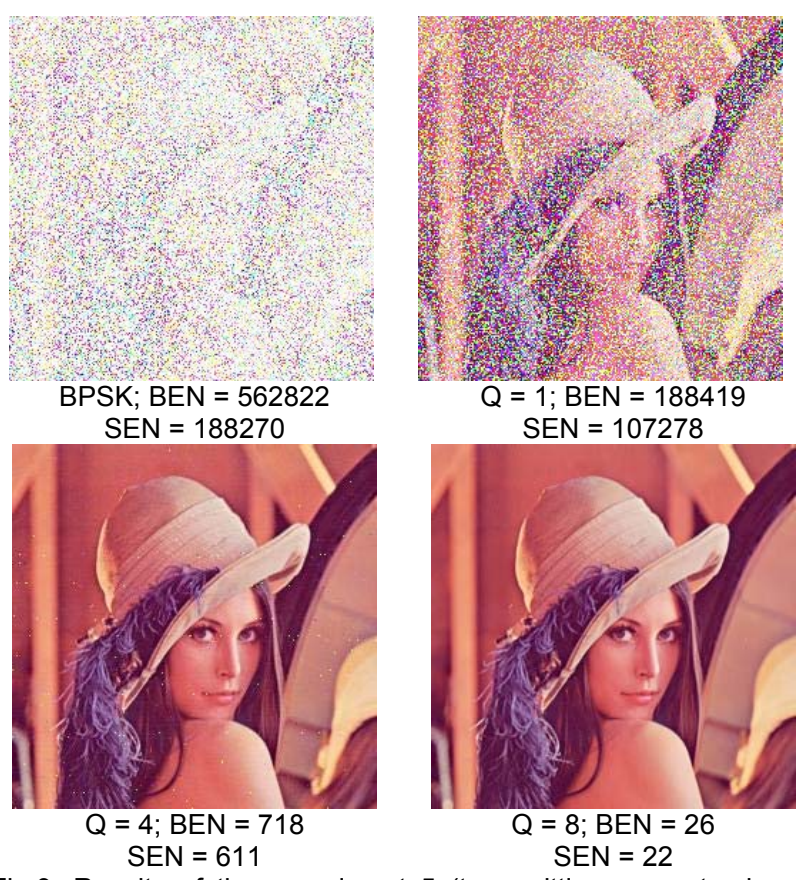

Fig.9. Results of the experiment 5 (transmitting computer image "lena.jpg")

So, the results of these experiments are shown high efficiency of the turbo-code. The PL-log-MAP algorithm is shown to have very good performance to use it as a main algorithm for turbo-decoder in WBAN communication unit [41-43].

\section{Conclusions}

At the time of the latest technology an information became the object of automated processing. There are many distributed computer systems with different functional purposes. The error-correcting task is one of the main for the system architect. The turbo-code evolution for the channels with AWGN and Rayleigh fadings has shown a very high potential of this coding technique at the low energy regions

This work is devoted to research actual scientific and practical task of increasing reliability of the transmitted data and reducing the computational decoding complexity by improving turbo-code design in WBAN. We use PL-log-MAP turbo-decoding algorithm in our experiments. It can reduces the computational complexity, and accordingly improves the performance of turbo-decoder, without significant loss in the data decoding efficiency. Experimental functions BER = $f\left(E_{b} / N_{0}\right)$ have been found, that can be used for further turbodecoder hardware-software implementation for WBAN communication unit.

Authors: D.Sc., Professor of Automatics and InformationMeasuring Techniques Department Roman N. Kvyetnyy, Vinnytsia National Technical University, Khmelnytsky Hwy, 95, 21021 Vinnitsa, Ukraine, e-mail: rkvetny@sprava.net; Yuriy Yu. Ivanov, Vinnytsia National Technical University, Khmelnytsky Hwy, 95, 21021 Vinnitsa, Ukraine, e-mail: rkvetny@sprava.net, Ph.D. Yaroslav A. Kulyk, National Technical University, Khmelnytsky Hwy, 95, 21021 Vinnitsa, Ukraine, e-mail: rkvetny@sprava.net; Prof. Waldemar Wójcik, Lublin University of Technology, Institute of Electronics and Information Technology, Nadbystrzycka 38A, 20618 Lublin, Poland, e-mail: waldemar.woicik@pollub.pl: M.Sc. Azhar Sagymbekova, International Information University (IITU), Almaty, Kazakhstan, email: asagymbekova@gmail.com; M.Sc. Nursanat Askarova, Almaty University of Power Engineering and Telecommunications (AUPET), email: nursanat@gmail.com. 


\section{REFERENCES}

[1] Liang Li., Analysis of Low Power Implementational Issues of Turbo-like Codes in Body Area Networks, Ph.D. dissertationUniversity of Southampton, England, (2009), 87

[2] Li H.-B., Takizawa K., Zhen B., Kohno, R., Body Area Network and Its Standardization at IEEE 802.15.MBAN", Proceedings on 16th Mobile and Wireless Communications Summit, Budapest, Hungary, (2007), 1-5

[3] Zhen B., Li H.-B., Kohno R., IEEE Body Area Networks for Medical Applications, Proceedings on 4th International Symposium on Wireless Communication Systems, (2007), 327331

[4] Kulyk A.Ya., Ivanov Yu.Yu., Ivanov I.Yu., The Turbo-codes Application in Telemedicine Systems with the Wireless Body Area Sensor Networks, Proceedings on 12th Int. Conf. on Control and Management in Complex Systems, (2014), 206

[5] Singh A., Kumar A., Kumar P., Body Sensor Network: A Modern Survey \& Performance Study in Medical Perspect, International Conference on Recent Trends in Applied Sciences with Engineering Applications, 3 (2013), 12-17

[6] Kwak K.S., Ullah S., Ullah, N., An Overview of IEEE 802.15.6 Standard, Proceedings on 3rd International Symposium on Applied Sciences in Biomedical and Communication Technologies (ISABEL), (2010), 1-5

[7] Chen M., Gonzalez S., Vasilakos A., et al., Body Area Networks: A Survey, Mobile Networks and Applications, 16 (2011), 171-193

[8] Islam M.R., Error Correction Codes in Wireless Sensor Network: An Energy Aware Approach, World Academy of Science, Engineering and Technology, 4 (2010), 535-540

[9] IEEE Standard for Local and Metropolitan Area Networks. Part 15.6: Wireless Body Area Networks, IEEE, (2012), 271

[10]Tanenbaum A.S., Wetherall D.J., Computer Networks, Prentice Hall, (2010), 3-89

[11]Berrou, C., Glavieux, A., Thitimajshima, P., Near Shannon Limit Error-Correcting Coding and Decoding: Turbo-Codes, Proceedings of ICC'93, (1993), 1064-1070

[12]Berrou, C., Douillard C., Jezequel, M., et. al., Channel Coding in Communication Networks. From Theory to Turbocodes, Chippenham, (2007), 255-371

[13] Ivanov Yu.Yu., Kulyk A.la., On Some Aspects of the Iterative Strategy of Turbo Decoding: Retrospective and "Turbo"principle, Proceedings of 4th International Scientific and Practical Conference Information Technologies and Computer Engineering, (2014), 157-160

[14]Douillard, C., Jezequel, M., et. al., Codes and Turbo Codes, Springer, (2010), 213-271

[15]Wu, Y., Implementation of Parallel and Serial Concatenated Convolutional Codes, Ph.D. dissertation Faculty of the Virginia Polytechnic Institute and State University, (2000)

[16] Ivanov Yu.Yu., Experimental Research of Turbo Codes ErrorCorrection Characteristics: Numerical Estimations and Simulation for Novel Suboptimal PL-Log-MAP Decoding Algorithm, Journal of Vinnytsia Polytechnical Institute, 5 (2016), 76-84

[17] Krak Yu.V., Dynamics of manipulation robots: Numericalanalytical method of formation and investigation of computational complexity, Journal of Automation and Information Sciences, (1999) 31, No.1-3, 121-128

[18] Surtel W., Maciejewski M., Różalski R., Architecture of a server application for use in environmental patient monitoring, Informatyka, Automatyka, Pomiary w Gospodarce i Ochronie Środowiska - IAPGOŚ, 3 (2013), No. 4, 35-37

[19] Krak Yu.V., Robot-manipulator's dynamics: numericalanalytical method of formation and investigation of calculation complexity, Problemy Upravleniya I Informatiki (Avtomatika), (1998), No. 2, 139-148

[20]Al-Maitah M., Timchenko L.I., Kokriatskaia N.I. et al., Parallelhierarchical network as the model of neurocomputing, Proceedings of SPIE 10808, (2018)

[21]Woodard J., Hanzo L., Comparative Study of Turbo Decoding Techniques: An Overview, IEEE Transactions on Vehicular Technology, 49 (2000), No. 6, 2208-2233

[22] Kulyk A., Ivanov Yu., Krivogubchenko S., A Viterbi Algorithm as a Key to Decoding Turbo-Code, Nauka i studia, Przemyst, 11(2012), 60-65

[23] Ivanov Yu.Yu., Hardware and Software Features of the Turbo Codes: Analysis of the Implementation Complexity on Digital
Signal Processor, Journal of Vinnytsia Polytechnical Institute, Vinnytsia, 3 (2016)

[24]Hanzo L., Liew T.H., Yeap B.L., Turbo Coding, Turbo Equalisation and Space-Time Coding for Transmission over Wireless Channels, Southampton, (2002), 107-170

[25] Ivanov Yu.Yu., Romanyuk A.N., Kulyk A.la., Stukach O.V., A Novel Suboptimal Piecewise-Linear-log-MAP Algorithm for Turbo Decoding, Proceedings of 11th IEEE International Siberian Conference on Control and Communications (SIBCON), (2015), 1-8

[26] Ivanov Yu.Yu., Stukach O.V., Romanyuk A.N., A Brief Overview and Experimental Researches of Novel PL-log-MAP Turbo Decoding Algorithm, Proceedings on 13th IEEE International Siberian Conference on Control and Communications (SIBCON), (2017), 1-6

[27] Kirichenko M.F., Krak Yu.V., Polishchuk A.A., Pseudo inverse and projective matrices in problems of synthesis of functional transformers, Kibernetika i Sistemnyj Analiz, 40 (2004), No. 3, 116-129

[28]Urbanovich P., Romanenko D., ShimanD., Vitkova M., Multithreshold majority decoding of LDPC-codes, IAPGOŚ, 2 (2012), No. 4a, 22-24

[29] Pavlov S.V., Kozhemiako V.P., Kolesnik P.F., et al., Physical principles of biomedical optics: monograph, VNTU, (2010), 152

[30] Borovska T. N., Bykov N. M., Raimyn A., Optimal equivalent models of import replacement and localization of production, Far East Journal of Electronics and Communications, 16 (2016), No. 1, 5 - 35

[31]Kvyetnyy R.N., Ivanov Yu.Yu., Krivogubchenko S.G., Stukach O.V., Features of Estimation the Transmission Data Process Using Turbo-Codes, Journal Metrology and Devices, 3 (2017), 25-32

[32] Jiang Y., A Practical Guide to Error-Control Coding Using MATLAB, Artech House, (2010), 213-251

[33]Vassilenko, Valtchev S., Teixeira J.P., Pavlov S., Energy harvesting: an interesting topic for education programs in engineering specialities, Internet, Education, Science, (2016), 149-156

[34]Pavlov S.V., Barylo A.S., Kozlovska T.I. et al., Analysis of microcirculatory disorders in inflammatory processes in the maxillofacial region on based of optoelectronic methods, Przegląd Elektrotechniczny, 93 (2017), No. 5, 114 -117

[35] Serkova V.K., Pavlov S.V., et al., Medical expert system for assessment of coronary heart disease destabilization based on the analysis of the level of soluble vascular adhesion molecules, Proc. SPIE 10445, (2017)

[36]Pavlov S. V., Sander S. V., Kozlovska T. I., Kaminsky A. S., Wójcik W., et al., Laser photoplethysmography in integrated evaluation of collateral circulation of lower extremities, Proc. SPIE 8698, (2013)

[37] Oleksiy D. Azarov, Oleksandr V. Dudnyk, Oleksandr V. Kaduk, Andrzej Smolarz, Aron Burlibay, "Method of correcting of the tracking ADC with weight redundancy conversion characteristic", Proc. SPIE 9816, Optical Fibers and Their Applications 2015, 98161V (17 December 2015).

[38]Azarov O.D., Murashchenko O.G., Chernyak O.I., Smolarz A., Kashaganova G., Method of glitch reduction in DAC with weight redundancy, Proc. SPIE 9816, (2015)

[39]Azarov O. D., Dudnyk O. D., Duk M., Porubov D., Static and dynamic characteristics of the self-calibrating multibit ADC analog components, Proc. SPIE 8698, (2013)

[40]Azarov D., Chernyak A. I., Chernyak P. A., Class of numerical systems for pipeline bit sequential development of multiple optoelectronic data streams, Proc. SPIE 4425, (2001).

[41] Osadchuk V.S., Osadchuk A.V., The Microelectronic Radiomeasuring Transducers of Magnetic Field with a Frequency Output, Electronics and Electrical Engineering, 110 (2011), No.4, 67-70

[42] Grigor'ev A. Ya., Zholtkevich G. N., Nosov K. V., Gamulya Yu. G., Bespalov Yu. G., Vysotskaya E. V., Pecherskaya A. I., Diskretnye modeli dinamicheskikh sistem, opredelyayushchikh stabil'nost' gidrobiotsenozov, Veterinarnaya meditsina, (2014), No. 99, 164-167

[43] Borovska T., Optimal Aggregation Models for the Problem of Minimizing the Total Expenses of Multiproduct Production, IEEE, (2016), 136-139 